Eur. J. Clin. Chem. Clin. Biochem.

Vol. 31, 1993, pp. 707-713

(C) 1993 Walter de Gruyter \& Co. Berlin $\cdot$ New York

\title{
Glycated LDL Concentrations in Non-Diabetic and Diabetic Subjects Measured with Monoclonal Antibodies Reactive with Glycated Apolipoprotein B Epitopes
}

\author{
By M. P. Cohen, G. Lautenslager and Elizabeth Shea \\ University City Science Center, Exocell, and the University of Pennsylvania Philadelphia, PA, U.S.A.
}

(Received March 8/August 12, 1993)

Summary: The potential importance of the non-enzymatic glycation of low density lipoproteins (LDL) in atherogenesis and in the accelerated atherosclerosis associated with diabetes is well recognized. However, it has been difficult to evaluate LDL glycation in the clinical setting because of the lack of suitable methods. To approach this problem, we produced monoclonal antibodies, designated ES12, that recognize glycated apolipoprotein B epitopes in the LDL complex in human plasma. Here we report the use of these antibodies in a competitive enzyme-linked immunosorbent assay (ELISA) to measure glycated LDL concentrations in plasma from non-diabetic and diabetic subjects. In this assay, glycated LDL in the soluble phase inhibits binding of the ES12 antibody to glycated LDL immobilized to microtitre wells, whereas other glycated proteins and non-glycated LDL do not compete. A linear dose-response relationship for 10-125 ng glycated LDL per well allows the construction of standard curves, from which the concentration of glycated LDL in human plasma can be determined. The mean concentration of glycated LDL in samples from non-diabetic subjects was $21.8 \pm 0.9 \mathrm{mg} / \mathrm{l}$, increasing to $40.8 \pm 2.6 \mathrm{mg} / \mathrm{l}$ in samples from patients with type II diabetes, comprising $1.9-4.8 \%$ and 3.2-14.8\%, respectively, of total apolipoprotein B. Glycated LDL concentrations in samples from diabetic patients correlated positively and significantly with other indices of glycaemic status. The results indicate that circulating glycated LDL, which may have diagnostic and pathophysiologic importance, is increased in diabetes with attendant hyperglycaemia. The results further indicate that the described monoclonal antibody=based competitive ELISA affords a simple and reproducible method for quantitative measurement of glycated LDL.

\section{Introduction}

Non-enzymatic glycation is a condensation reaction between glucose and reactive protein amino groups at the $\mathrm{NH}_{2}$-terminus or $\varepsilon$-amino groups of lysine residues. In diabetic subjects, hyperglycaemia promotes increased non-enzymatic glycation of circulating and tissue proteins, thereby allowing assessment of integrated glycaemic control through determination of glycohaemoglobin and glycoalbumin concentrations, and also providing insight into pathogenetic mechanisms associated with chronic complications of diabetes. The non-enzymatic glycation of apolipoprotein B, the principal protein of the cholesterol-carrying low density lipoproteins (LDL), has generated con- siderable interest, because it has been implicated in the premature and severe atherosclerosis associated with diabetes mellitus, and LDL glycation is one of the post-secretory modifications believed to affect its atherogenic potential. For example, internalization and degradation by cultured fibroblasts of LDL from patients with insulin-dependent diabetes and poor metabolic control is decreased, compared with that of LDL isolated from normal subjects or from patients with insulin-dependent diabetes and good metabolic control (1). Glycation of LDL diminishes the high affinity LDL receptor-mediated uptake and degradation of LDL $(2-7)$, and may promote internalization by alternative receptors of monocyte-mac- 
rophages that give rise to foam cells $(8-12)$. Additionally, glycation alters the rate of clearance of LDL in vivo, and may interfere with intracellular handling of cholesterol and regulation of its synthesis $(4,13$, 16). Further, non-enzymatically glycated proteins may have accelerated rates of free radical production (17, 18), which could increase lipid peroxidation and thereby enhance LDL atherogenicity through formation of modified apolipoprotein B adducts that are recognized and internalized by the classic macrophage scavenger receptor $(19-21)$. Some $(22,23)$ but not all (24) investigators propose that glucose auto-oxidation and sequential modification by glycation and oxidation ("glycoxidation") contribute to increased atherogenesis in diabetes.

Although the potential importance of elevated glycated LDL concentrations in atherogenesis is well recognized, suitable methods for quantitative analysis of plasma glycated LDL have been lacking. To approach this problem, we established hybridomas secreting monoclonal antibodies that recognize glycated epitopes residing in the apolipoprotein B of the LDL complex but not in other plasma proteins (25). These antibodies, which have been designated ES12, react on Western blotting and in immunoassay with polypeptides in the LDL complex in human plasma; the polypeptides show co-identity with apolipoprotein B on separate immunoblotting when reacted with apolipoprotein B-specific monoclonal antibodies. In the present study, we report measurement of glycated LDL in human plasma with a competitive enzymelinked immunosorbent assay (ELISA) that employs the ES12 monoclonal antibodies. Results are expressed as $\mu \mathrm{g}$ (glycated) apolipoprotein B equivalents, and can be converted to the fraction (percent) of apolipoprotein $B$ that is glycated by dividing by the total apolipoprotein B concentration, measured independently, in a sample. With this assay, the concentration of glycated LDL in plasma obtained from patients with type II diabetes was approximately one and a half fold greater than that found in samples from non-diabetic individuals, and correlated with other indices of integrated glycaemic status.

\section{Materials and Methods}

\section{Preparation of glycated proteins}

Glycated LDL was isolated from human LDL (Sigma Chem Co.) by chromatography on a column of phenylboronate agarose, which binds cis-diol groups of sugars. Some LDL preparations were chromatographed without pretreatment, while others were first subjected to glycation in vitro. LDL preparations were first examined for contaminating immunoglobulins which, if present, were removed by immunoadsorption with anti-human immunoglobulin polyclonal antibody. After equilibration and washing, the glycated protein was eluted from the phenylboronate agarose column with $100 \mathrm{mmol} / \mathrm{l}$ sorbitol (26). The amount of glycated LDL in the eluant was determined as apolipoprotein B equivalents, measured as micrograms apolipoprotein B by competitive immunoassay using a murine monoclonal antibody B36 (see below) which had been raised against purified human apolipoprotein B-100 (Scripps Laboratories, San Diego, CA). In vitro glycation was performed by incubating LDL for five days at room temperature under a nitrogen atmosphere in $0.15 \mathrm{~mol} / \mathrm{l}$ saline/1 mmol/1 EDTA, pH 7.4, containing $5 \mathrm{~g} / \mathrm{l}$ glucose, followed by dialysis against saline/EDTA to remove unbound glucose. Unretained material from the loading of the phenylboronate agarose column was used as a source of non-glycated protein.

Glycated albumin was purified from human plasma by sequential chromatography on Affi-gel blue and phenylboronate agarose as described (27). Glycated haemoglobin was purified from lysates of human erythrocytes by sequential ion exchange (BioRex 70) and affinity (phenylboronate agarose) chromatography (26).

\section{Generation of monoclonal antibodies}

The production and partial characterization of the ES12 monoclonal antibodies to glycated LDL has been described (25). In brief, male BALB/c mice were immunized by intraperitoneal injection of glycated apolipoprotein B, which was prepared by incubation of purified apolipoprotein B with $5 \mathrm{~g} / \mathrm{l}$ glucose in saline/EDTA for three days, followed by dialysis and affinity chromatography on phenylboronate agarose. Spleen cells from immunized animals were fused with SP $2 / 0$ myeloma cells and hybridoma colonies were established according to standard techniques (28). The resulting colonies, which displayed preferential binding activity to glycated apolipoprotein $B$ and to glycated LDL in direct ELISA, were cloned at least three times by limiting dilution. The colony designated ES12 secreted antibodies discriminating between glycated versus non-glycated apolipoprotein B and exhibiting the same discrimination for glycated versus non-glycated LDL. On immunoblotting and in direct ELISA these antibodies reacted with glycated epitopes residing within the apolipoprotein $B$ of the LDL complex, did not react with non-glycated LDL, and did not react with other circulating proteins, whether glycated or not (25). Metal-catalysed oxidation of glycated LDI abolished reactivity with the antibodies, indicating that the recognized epitope is glucosemodified and not a lipid oxidation or glycoxidation product (25). The ES12 antibodies, shown by Ouchterlony diffusion to be of the $\mathrm{IgG}_{1}$ class, were purified from culture supernatant or from mouse ascites fluid by protein $\mathrm{G}$ affinity chromatography, and used for development of a competitive ELISA for measuring glycated LDL in human plasma.

Antibodies to the apolipoprotein $\mathrm{B}$ were generated in male $\mathrm{BALB} / \mathrm{c}$ mice following the schedule described above, using apolipoprotein B-100 (Scripps Laboratories) as immunogen. The colony designated B36 secreted antibodies recognizing purified apolipoprotein B-100 (Scripps) and apolipoprotein B in LDL (Sigma Chem Co) and unreactive with apolipoprotein AI or high density lipoprotein (Sigma) (25). The B36 antibodies do not discriminate between glycated versus non-glycated apolipoprotein B. The B36 antibodies, which are of the IgG, class, were purified from mouse ascites fluid by protein $G$ affinity chromatography and used for development of the competitive ELISA for measuring apolipoprotein $\mathrm{B}$.

\section{Competitive ELISA for glycated LDL}

- Plastic microtitre wells (Nunc Polysorb) were coated with antigen ( $250 \mathrm{ng}$ protein per well) by incubation for 18 hours at room temperature in carbonate-bicąrbonate coupling buffer, $\mathrm{pH}$ 8.5. After washing to remove unbound material, wells were blocked with $0.1 \mathrm{~mol} / \mathrm{l}$ Tris $\mathrm{HCl}, \mathrm{pH} 7.5$, containing fetal bovine 
serum, volume fraction 0.1 , and stored at $4^{\circ} \mathrm{C}$ in the same buffer until use. The wash buffer contained $0.05 \mathrm{~mol} / \mathrm{l}$ triethylamine, $0.5 \mathrm{~g} / 1$ Tween-20 in saline, $\mathrm{pH}$ 7.2. To initiate the assay, the plates are washed and standard or sample in $50 \mu \mathrm{l}$ of assay buffer $(0.1 \mathrm{~mol} / 1$ Tris $\mathrm{HCl}, \mathrm{pH} 7.5$, containing fetal bovine serum, volume fraction 0.1 , and $2 \mathrm{~g} / \mathrm{l}$ Tween-20), is added. Monoclonal antibody ES12 diluted in buffer ( $3 \mu \mathrm{g}$ per well) is added immediately thereafter, and the plates are incubated at room temperature for 1 hour. After washing, horse radish peroxidase-conjugated goat anti-mouse $\operatorname{IgG}(1: 2000$ in 0.1 $\mathrm{mol} / \mathrm{l}$ Tris containing fetal bovine serum, volume fraction 0.1 ) is added and incubation proceeds for 1 hour. The plates are washed again, followed by addition of substrate (TMBlue microwell peroxidase system) and stopper $\left(1 \mathrm{~mol} / 1 \mathrm{H}_{2} \mathrm{SO}_{4}\right)$. Absorbances are read at $450 \mathrm{~nm}$.

\section{Analysis}

Apolipoprotein B was measured by competitive ELISA, in which apolipoprotein $B$ was immobilized onto plastic microtitre wells (Costar) by overnight incubation at room temperature in carbonate coating buffer, followed by washing, blocking and storage as above. After washing, the assay was initiated by addition of standard or sample in assay buffer followed by the B36 antibody ( $1 \mu \mathrm{g}$ per well), and the plates were incubated for 30 minutes at room temperature. Development and detection were accomplished with horseradish peroxidase conjugated goat anti-mouse IgG and substrate, as described above. The assay yields an inverse linear dose-response relationship between 0.25 and $2.0 \mu \mathrm{g}$ of apolipoprotein B. The competitive ELISA for apolipoprotein B was used to measure concentrations of apolipoprotein B in the glycated LDL preparations (for standardization of the glycated LDL competitive assay), and in the human plasma samples, allowing expression of results from the glycated LDL assay as the percentage of total apolipoprotein B that is glycated.

\section{Results}

The ES12 monoclonal antibodies used in these experiments recognize epitopes contained within high molecular mass polypeptides of purified glycated LDL; identical bands were visualized when human plasma was transferred to nitrocellulose after SDS gel electrophoresis and immunoblotted with the ES12 antibody (25). These polypeptide bands have been shown to have co-identity with apolipoprotein $B$ by separate immunoblotting with the B36 monoclonal antibody, which was raised against apolipoprotein B-100 and does not discriminate between glycated versus nonglycated apolipoprotein $\ddot{B}(25)$.

Glycated LDL added in the soluble phase with the ES12 monoclonal antibody competitively inhibited binding of the antibody to glycated LDL immobilized onto the microtitre wells. The phenylboronate agarose-adsorbed fraction of unincubated LDL or glucose-incubated LDL contained glycated LDL that immunoreacted in competitive ELISA with the ES12 antibody, whereas unretained material from the phenylboronate agarose did not react (fig. 1). LDL glycated in vitro exhibited immunoreactivity identical to "in vivo" glycated LDL on Western blotting (not
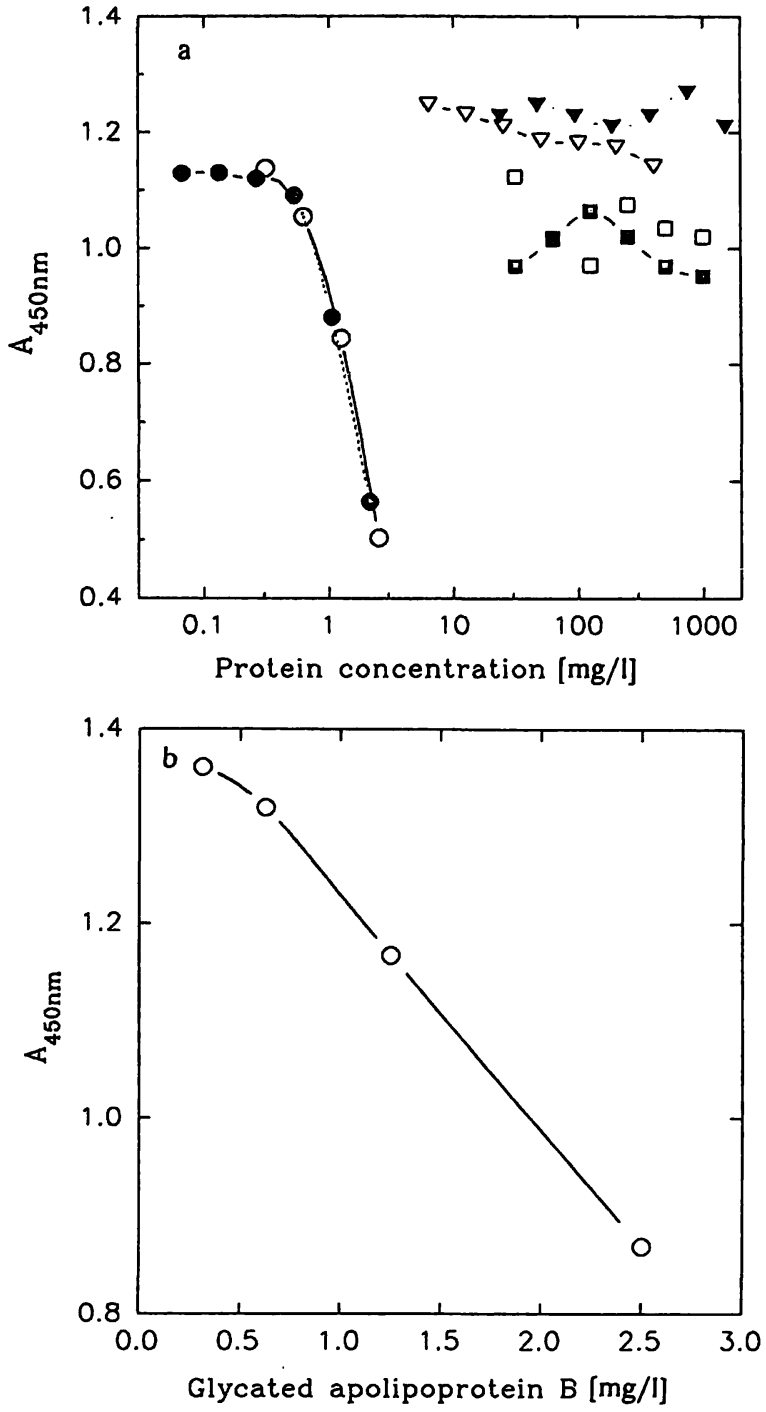

Fig. 1. Competitive immunoassay of glycated LDL

a) Experimental conditions: $250 \mathrm{ng}$ of glycated LDL (phenylboronate agarose-adsorbed fraction) immobilized onto plastic microtitre wells were incubated with variable amounts of candidate antigens and ES12 monoclonal antibody ( $3 \mu \mathrm{g}$ per well) in the soluble phase. Glycated LDL used for competition was represented by phenylboronate agarose-adsorbed protein in non-incubated (open circles, solid line) or glucose-incubated (closed circles, dashed line) material. Development and detection were with horseradish peroxidase-conjugated goat anti-mouse $\mathrm{IgG}$ and substrate, as described in the text. Concentrations of apolipoprotein B in the glycated LDL preparations were measured by competitive immunoassay with the B36 antibody as described in $\mathrm{Ma}$ terials and Methods. Other non-enzymatically glycated proteins (glycohaemoglobin = closed triangles; glycoalbumin $=$ open triangles) did not compete for binding with the ES12 monoclonal antibody. Nonglycated LDL (closed squares) and human serum albumin (open squares) did not compete for binding.

b) Linear dose response curve in the competitive assay using $10-125 \mathrm{ng}$ per well of glycated LDL in the soluble phase.

shown) and in competitive ELISA with the ES12 antibody (fig. 1). In contrast, purified preparations of other glycated proteins (glycated albumin, glycated haemoglobin), or of non-glycated LDL or human 
albumin added to the soluble phase, did not inhibit ES12 binding to the immobilized glycated LDL (fig. 1), thereby corroborating the specificity of the antibody for glycated epitopes residing in the LDL complex. Glycated LDL exhibited an inverse linear dose response between 10 and $125 \mathrm{ng}$ per well (fig $1 \mathrm{~b}$ ); plasma samples therefore were assayed at dilutions expected to yield concentrations within this range. Estimating that glycated LDL could comprise $1-10 \%$ of total apolipoprotein $B$, which has a normal range of approximately $0.3-1.5 \mathrm{~g} / \mathrm{l}$, the concentration of glycated LDL (as glycated apolipoprotein $B$ equivalents) would be in the range of $3-150 \mathrm{mg} / \mathrm{l}$. Samples were therefore diluted $1: 16-1: 20$ in assay buffer before addition of $50 \mu \mathrm{l}$ aliquots to the wells.

Figure 2 presents glycated LDL concentrations, expressed as $\mathrm{mg} / \mathrm{l}$, in 22 non-diabetic and 18 diabetic specimens. Concentrations ranged from $9-26 \mathrm{mg} / 1$ in non-diabetic and from $20-56 \mathrm{mg} / \mathrm{l}$ in diabetic samples. The difference between mean values in nondiabetic and diabetic samples was statistically significant. Calculated as the fraction (percent) of total apolipoprotein B that is glycated, values ranged from $1.9-4.8 \%$ in non-diabetic subjects and from 3.2$14.8 \%$ in diabetic patients (fig. 2). Mean intra-assay and inter-assay coefficients of variation were $7 \%$ and $10 \%$, respectively, in 4 measurements in each of 4 samples.

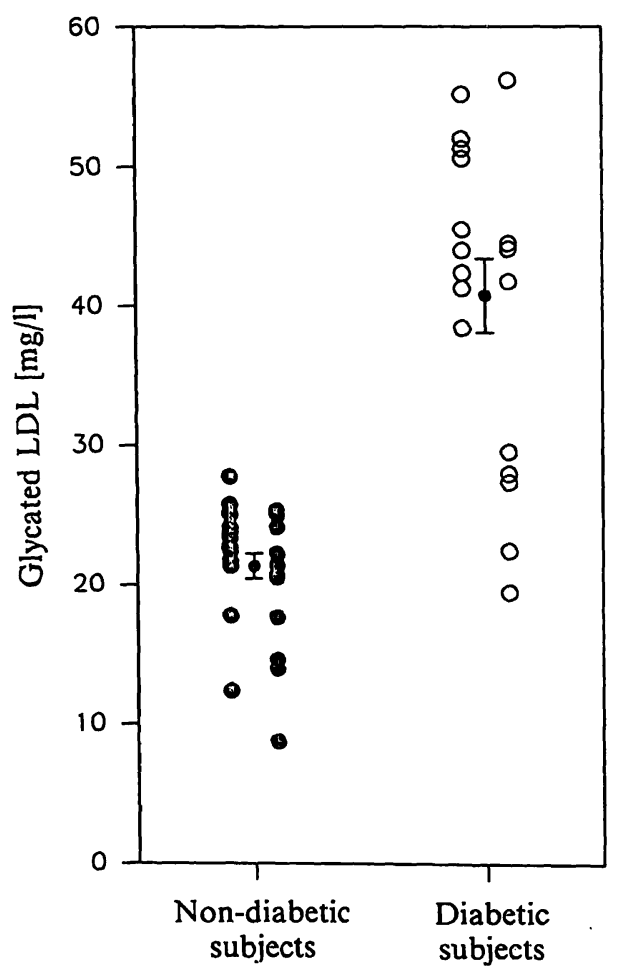

Fig. 2. Glycated LDL concentrations in plasma specimens from non-diabetic and diabetic subjects. Each point represents a value from an individual subject, determined in duplicate. Bars show mean and standard errors in each group. Non-diabetic versus diabetic, $\mathrm{p}<0.05$.
The samples from diabetic subjects were obtained from patients with type II diabetes whose therapeutic regimens had not changed during the three months before the samples were drawn. Eight were receiving a single injection of intermediate-acting insulin, ten were receiving an oral hypoglycaemic agent, and none was performing home-glucose monitoring. Concentrations of glycohaemoglobin and glycoalbumin in samples obtained on the same day as those used for glycated LDL analysis ranged from 7.7 to $15.0 \%$ and 1.1 to $3.7 \%$, respectively, indicating varying degrees of integrated glycaemic control, as would be anticipated in patients on unchanging therapeutic programmes. In these patients, the correlation ( $r$ ) value between glycohaemoglobin and glycoalbumin was 0.86 , indicating that integrated glycaemia during the two weeks before sampling approximated that during the 2-3 months before sampling; in other words, patients with elevated glycohaemoglobin also had increased glycoalbumin concentrations, reflecting chronic and unchanged hyperglycaemia during the preceding 2-10 weeks, whereas patients with normal glycohaemoglobin also had normal glycoalbumin concentrations, reflecting stability of glycaemic control during the preceding 2-10 weeks. Therefore, correlation of glycated LDL concentrations with these other indicators of integrated glycaemic control was sought, on the assumption that ambient glycaemia

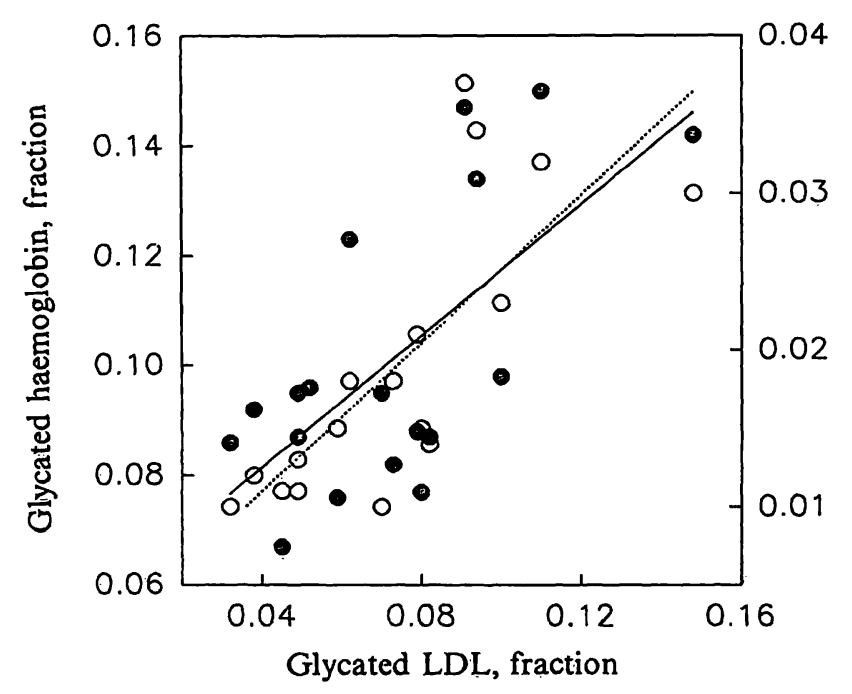

Fig. 3. Correlations between glycohaemoglobin (closed circles; solid line) or glycoalbumin (open circles; dashed line) and glycated LDL concentrations in simultaneously drawn samples taken from diabetic subjects. Glycohaemoglobin measured by phenylboronate agarose affinity chromatography (Isolab; Akron, Ohio), with normal, intermediate and elevated ranges established by the manufacturer as $6-8 \%, 10-12 \%$ and $14-16 \%$, respectively. Glycoalbumin measured by ELISA (Exocell, Philadelphia, PA), with upper limit of normal range established by the manufacturer as $2.4 \pm 0.29 \%$. Glycohaemoglobin vs. glycated LDL, $r=0.67$; glycoalbumin vs. glycated $L D L, r=0.77$. 
during the week before sampling (estimated circulating half-life of LDL is 3-5 days (29)) in these subjects probably approximated that during the preceding 2-10 weeks. Figure 3 illustrates these correlations with $r$ values of 0.67 between glycohaemoglobin and glycated LDL concentrations, and 0.77 between glycoalbumin and glycated LDL concentrations.

\section{Discussion}

In developing an immunoassay for glycated LDL, we considered it important that the antibodies used in the assay discriminate between glycated versus nonglycated or oxidatively modified LDL, that they react with Amadori products of the glycated protein, and that they distinguish glycated LDL from other circulating glycated proteins. The desirability of antibodies with these characteristics is clear, since the much greater plasma concentration of non-glycated LDL or other glycated protein (e.g. albumin) would obfuscate results if the antibodies lacked adequate discrimination. Similarly, cross-reactivity with lipid oxidation products might confuse the assay results. Further, the Amadori rearrangement of the condensation reaction between glucose and reactive protein amino groups is the predominant form in which nonenzymatically glycated proteins exist in vivo. The ES12 monoclonal antibody satisfies these requirements, given that it does not react with non-glycated apolipoprotein $\mathrm{B} / \mathrm{LDL}$ or with other circulating proteins, whether glycated or not, recognizes glycated LDL formed in vivo, consistent with the Amadori product, and does not recognize oxidatively or glycoxidatively modified LDL (25).

Apolipoprotein $B$ is the principal protein of $L D L$, the major carrier of plasma cholesterol. Apolipoprotein $B$ is a complex macromolecule that exists in two primary forms in human plasma $(30,31)$, and it is the protein determinant for the cellular recognition and uptake of LDL by the LDL receptor $(32-35)$. The binding of apolipoprotein B to the LDL receptor results in internalization and degradation of LDL, promoting the clearance of LDL from the plasma and regulating intracellular cholesterol handling and biosynthesis (36-38). Glycation of lysine residues in apolipoprotein B may compromise receptor-mediated internalization and catabolism of LDL, thereby interfering with cholesterol homeostasis and contributing to the pathogenesis of atherosclerosis $(1,4-8$, $13,16,39)$. Thus, direct assessment of LDL glycation may have diagnostic and epidemiologic importance as a bio-marker for atherogenic risk, especially in diabetic populations. Additionally, the 3-5 day circulating half-life of LDL (29) suggests that measure- ment of glycated LDL could provide an objective index of integrated short-term glycaemic control in diabetic subjects, although there are reports that glycation can prolong or accelerate LDL clearance (2, $13,15,40,41)$.

The results presented in this study demonstrate that plasma glycated LDL concentrations can be specifically measured by enzyme-linked immunosorbent assay using a unique and highly specific monoclonal antibody that recognizes glycated apolipoprotein B epitopes in the LDL complex (25). The assay shows a linear dose response at concentrations between 0.2 and $2.5 \mathrm{mg} / 1$ ( 10 to $125 \mathrm{ng}$ per $50 \mu \mathrm{l}$ aliquot), encompassing the range found in a $50 \mu$ laliquot of plasma diluted $1: 20$ for assay $(20-60 \mathrm{mg} / \mathrm{l} ; 50-150 \mathrm{ng}$ in $50 \mu$ of $1: 20$ dilution). Plasma glycated LDL concentrations in diabetic subjects were found to be significantly greater than in non-diabetic subjects and, in patients in whom therapy had remained unchanged for 2-3 months before sampling, showed positive and significant correlation with glycohaemoglobin and glycoalbumin concentrations. The amount of glycated LDL determined with this assay, expressed as percent of total apolipoprotein B that is glycated, is consistent with that estimated in previous studies using phenylboronate agarose affinity chromatography to separate glycated LDL $(42-44)$.

Previously, measurement of the amount of glycated LDL has required isolation of the LDL complex followed by separation of glycated from non-glycated species with affinity chromatography on phenylboronate, then determination of the amount of LDL in the different fractions by gel electrophoresis with densitometric scanning or by immunochemical analysis. The competitive ELISA described herein does not require extraction, chromatography, or sample pretreatment (other than dilution), and can easily be completed within two hours. Results are quantitative and reproducible and confirm that non-enzymatic glycation of LDL, like that of other circulating proteins, is increased in diabetes with attendant hyperglycaemia. The availability of this assay should allow epidemiologic studies and correlative analyses in diabetic populations for assessing the predictive value and risk for atherosclerotic disease associated with elevated levels of glycated LDL. Measurement of glycated LDL could also provide an index of shortterm integrated glycaemia that may prove clinically useful in the management of diabetes.

\section{Acknowledgement}

Supported in part by Grant No. DK 44386 from the Department of Human and Health Services. 


\section{References}

1. Lopez-Virella, M. F., Sherer, G. K., Lees, A. M., Wohltman, H., Mayfield, R. K., Sagel, J., Leroy, E. C. \& Colwell, J. A. (1982) Surface binding, internalization and degradation by cultured human fibroblasts of low density lipoproteins isolated from Type I (insulin-dependent) diabetic patients: Changes with metabolic control. Diabetologia 22, $430-436$.

2. Witztum, J. L., Mahoney, E. M., Branks, M. J., Fisher, M., Elam, R. \& Steinberg, D. (1982) Nonenzymatic glucosylation of low density lipoproteins alters its biologic activity. Diabetes 31, 283-291.

3. Sasaki, J. \& Cottam, G. L. (1982) Glycosylation of human LDL and its metabolism in human skin fibroblasts. Biochem. Biophys. Res. Comm. 104, 977-983.

4. Sasaki, J. \& Cottam, G. L. (1982) Glycosylation of LDL decreases its ability to interact with high affinity receptors of human fibroblasts in vitro and decreases its clearance from rabbit plasma in vivo. Biochim. Biophys. Acta 713, 199-207.

4. Gonen, G., Baenziger, J., Schonfeld, G., Jacobson, D. \& Farrar, P. (1981) Nonenzymatic glycosylation of low density lipoproteins in vitro: Effects of cell-interactive properties. Diabetes 30, 875-878.

6. Lorenzi, M., Cagliero, E., Markey, B., Hendriksen, T., Witztum, J. L. \& Sampietro, T. (1984) Interaction of human endothelial cells with elevated glucose concentrations and native and glycosylated low density lipoproteins. Diabetologia 26, 218-222.

7. Klein, R. L., Lyons, T. J. \& Lopes-Virella, M. F. (1990) Metabolism of very low- and low-density lipoproteins isolated from normolipidemic Type II (non-insulin-dependent) diabetic patients by human monocyte derived macrophages. Diabetologia 33, 299-306.

8. Klein, R. L., Lyons, T. J. \& Lopes-Virella, M. F. (1989) Interaction of very low density lipoproteins isolated from Type I (insulin-dependent) diabetic subjects with human monocyte derived macrophage. Metabolism 38, 11081113.

9. Fogelman, A. M., Schechter, J. S., Seager, J., Hokum, M., Child, J. S. \& Edwards, P. A. (1980) Malondialdehyde alteration of low density lipoprotein leads to cholesterol accumulation in human monocyte-macrophages. Proc. Natl. Acad. Sci. USA 77, 2214-2218.

10. Haberland, M. E., Fogelman, A. M. \& Edwards, P. A. (1982) Specificity of receptor-mediated recognition of malondialdehyde-modified low density lipoproteins. Proc. Natl. Acad. Sci. USA 79, 1712-1716.

11. Goldstein, S. L., Ho, Y. K., Basu, S. K. \& Brown, M. S. (1979) Binding site on macrophages that mediates uptake and degradation of acetylated low density lipoprotein, producing massive cholesterol deposition. Proc. Natl. Acad. Sci. USA 76, 333-337.

12. Brown, M. S. \& Goldstein, J. L. (1990) Scavenging for receptors. Nature (Lond) 343, 508-509.

13. Steinbrecher, U. P. \& Witztum, J. L. (1984) Glucosylation of low-density lipoproteins to an extent comparable to that seen in diabetes slows their catabolism. Diabetes 33,130134.

14. Lopez-Virella, M. F., Klein, R. L., Lyons, T. J., Stevenson, H. C. \& Witztum, J. L. (1988) Glycosylation of low-density lipoproteins enhances cholesteryl ester synthesis in human monocyte-derived macrophages. Diabetes 37, 550-557.

15. Kortlandt, W., Benschop, C., van Rijn, H. J. M. \& Erkelens, D. W. (1992) Glycated low density lipoprotein catabolism is incresed in rabbits with alloxan-induced diabetes mellitus. Diabetologia 35, 202-207.
16. Lyons, T. J., Klein, R. L., Baynes, J. W., Stevenson, H. C. \& Lopes-Virella, M. F. (1987) Stimulation of cholesterylester synthesis in human monocyte-derived macrophages by low density lipoproteins from Type I (insulin dependent) diabetic patients: the influence of nonenzymatic glycosylation of low density lipoprotein. Diabetologia 30, 916-923.

17. Gillery, P., Monboisse, J. C., Maquart, F. X. \& Borel, J. P. (1988) Glycation of proteins as a source of superoxide. Diabete \& Metabolisme 14, 25-30.

18. Mullarkey, C. J., Edelstein, D. \& Brownlee, M. (1990) Free radical generation by early glycation products: A mechanism for accelerated atherogenesis in diabetes. Biochem. Biophys. Res. Comm. 173, 932-939.

19. Quinn, M. T., Parthasarathy, S., Fong, L. G. \& Steinberg, D. (1987) Oxidatively modified low density lipoproteins: A potential role in recruitment and retention of monocytemacrophages during atherogenesis. Proc. Natl. Acad. Sci. USA 84, 2995-2998.

20. Sparrow, C. P., Parthasarathy, S. \& Steinberg, D. (1987) A macrophage receptor that recognizes oxidized LDL but not acetylated LDL. J. Biol. Chem. 264, 2599-2604.

21. Steinberg, D., Parthasarathy, S., Carew, T. E., Khoo, J. C. \& Witztum, J. L. (1989) Beyond cholesterol: Modifications of low density lipoprotein that increase its atherogenicity. N. Engl. J. Med. 320, 915-924.

22. Lyons, T. J. (1991) Oxidized low density lipoproteins - A role in the pathogenesis of atherosclerosis in diabetes? $\mathrm{Di}$ abetic Med. 8, $411-419$.

23. Wolf, S. \& Dean, R. T. (1987) Monosaccharide autoxidation: A potential source of oxidative stress in diabetes? Model reactions with nucleotides and protein. Bioelectrochem. Bioenerg. 18, 283-293.

24. Babiy, A. V., Gebicki, J. M., Sullivan, D. R. \& Wiley, K. (1992) Increased oxidizability of plasma lipoproteins in diabetic patients can be decreased by probucol therapy and is not due to glycation. Biochem. Pharmacol. 43, 9951000.

25. Shea, E. \& Cohen, M. P. (1993) Immunologic detection of glycated apolipoprotein B with site specific monoclonal antibodies. J. Immunol. Meth. 163, 85-95.

26. Steward, L. A., Wu, V. Y., Shea, E. \& Cohen, M. P. (1991) Production and characterization of monoclonal antibodies against non- $A_{1 c}$ glycated hemoglobin. J. Immunol. Meth. $140,145-151$.

27. Cohen, M. P. \& Hud, E. (1989) Production and characterization of monoclonal antibodies against human glycoalbumin. J. Immunol. Meth. 117, 121-129.

28. Kennet, R. H., McKearn, T. J. \& Bechtol, B. K. (1982) Monoclonal Antibodies Hybridomas. A New Dimension in Biological Analyses. Plenum Press, New York.

29. Gitlin, D., Cornwell, D. G., Nakasato, D., Oncley, J. L., Hughes, W. I. \& Janeway, C. A. (1958) Studies on the metabolism of plasma proteins in nephrotic syndrome. (II. The Lipoproteins). J. Clin. Invest. 37, 172-184.

30. Kane, J. P., Hardman, D. A. \& Paulus, H. E. (1980) Heterogeneity of apolipoprotein B: Isolation of a new species from human chylomicrons. Proc. Natl. Acad. Sci. USA $77,2465-2469$.

31. Kane, J. P. (1983) Apolipoprotein B structural and metabolic heterogeneity. Annu. Rev. Physiol. 45, 637-650.

32. Elovson, J., Jacobs, J. C., Schumaker, V. N. \& Puppione, D. L. (1985) Molecular weights of apoprotein B obtained from human low-density lipoprotein (Apoprotein B-PI) and from rat very low density lipoprotein (Apoprotein B-PIIII). Biochemistry 24, 1569-1578. 
33. Milne, R., Theolis, R., Maurice, R. J., Pease, P. K., Weech, E., Rassart, J. C., Fruchart, J. S. \& Marcel, Y. L. (1989) The use of monoclonal antibodies to localize the low density lipoprotein receptor-binding domain of apolipoprotein B. J. Biol. Chem. 264, 19754-19760.

34. Welty, F. K., Hubl, S. T., Pierotti, V. R. \& Young, S. G. (1991) A truncated species of apolipoprotein B (B67) in a kindred with familial hypobeta-lipoproteinemia. J. Clin. Invest. 87, $1748-1754$.

35. Clardaras, C., Hadzopoulou-Clardaras, M., Nolte, R. T., Atkinson, D. \& Zannis, V. I. (1986) The complete sequence and structural analysis of human apolipoprotein B-100: Relationship between apo B-100 and apo B-48. EMBO J. 5, 3495-3507.

36. Goldstein, J. L. \& Brown, M. S. (1977) The low density lipoprotein pathway and its relation to atherosclerosis. Annu. Rev. Biochem. 46, 897-930.

37. Brown, M. S., Kovanen, P. T. \& Goldstein, J. L. (1981) Regulation of plasma cholesterol by lipoprotein receptors. Science 212, 628-635.

38. Brown, M. S. \& Goldstein, J. L. (1983) Familial hypercholesterolemia. In: The Metabolic Basis of Inherited Human Disease (Stanbury, J. B., Wyngarden, J. B., Frederickson, D. S., Goldstein, J. F. \& Brown, M. S., eds) McGraw-Hill, New York, pp. 500-550.
39. Triau, J. E., Arbetter, J. \& Schaefer, E. J. (1986) Impaired hepatocyte binding, uptake and degradation of glucosylated low density lipoproteins. Biochim. Biophys. Acta 877, $359-365$

40. Kesaniemi, Y. A., Witztum, J. L. \& Steinbrecher, U. P. (1983) Receptor-mediated catabolism of low density lipoprotein in man. Quantitation using glucosylated low density lipoprotein. J. Clin. Invest. 71, 950-959.

41. Wiklund, O., Witztum, J. L., Carew, T. E., Pittman, R. C., Elam, R. L. \& Steinberg, D. (1987) Turnover and tissue sites of degradation of glucosylated low density lipoprotein in normal and immunized rabbits. J. Lipid Res. 28, $1098-$ 1109.

42. Lyons, T. J., Baynes, J. W., Patrick, J. S., Colwell, J. A. \& Lopes-Virella, M. F. (1986) Glycosylation of low density lipoprotein in patients with Type I (insulin-dependent) diabetes: Correlations with other parameters of glycemic control. Diabetologia 29, 685-689.

43. Jack, C. M., Sheridan, B. \& Kennedy, L. (1988) Nonenzymatic glycosylation of low density lipoproteins. Results of an affinity chromatography method. Diabetologia 31, $126-128$.

44. Tames, F. J., Mackness, M. I., Anol, S., Laing, I. \& Durrington, P. N. (1992) Nonenzymatic glycation of apolipoprotein $B$ in the sera of diabetic and nondiabetic subjects. Atherosclerosis 93, 237-244.

Margo P. Cohen, M. D.

3508 Market Street

Suite 420

Philadelphia, PA 19104

U.S.A. 
- 